\title{
Categorizing expressive speech acts in the pragmatically annotated SPICE Ireland corpus
}

\author{
Patricia Ronan, Université de Lausanne
}

\begin{abstract}
Expressive speech acts are one of the five basic categories of speech acts identified by Searle (1976). Expressives remain underresearched, though select categories of expressive speech acts, especially offering thanks and compliments, have received more extensive attention. An overall classification of expressive speech acts on the basis of corpus data has not yet been carried out. The current study provides a first survey of different types of expressive speech acts on the basis of three categories of spoken Irish English of different levels of formality: broadcast discussion, classroom discussion and face-to-face interaction. The data are extracted from the pragmatically tagged SPICE-Ireland corpus, a member of the International Corpus of English-family of corpora. The aim of the current study is to offer an overview and classification of expressives in the corpus material. Eight distinct subcategories of expressive speech acts are identified in this study. These categories are agreement, disagreement, volition, offering thanks, apologies, exclamations, expressions of sorrow and greetings.
\end{abstract}

\section{$1 \quad$ Introduction}

The division of speech acts into different subcategories largely goes back to the work of Austin (1962) and Searle $(1969,1976)$. Of Searle's five basic categories, representatives, directives, commissives, declarations and expressives, the first three have received considerable attention, while the latter two are less well researched. There is a particular dearth of research on expressive speech acts (Guiraud et al. 2011: 1031). So far mainly select categories of expressive speech acts have been investigated by corpus linguistic approaches, these are especially thanking and more general politeness (Taavitsainen and Jucker 2010) and compliments (Jucker et al. 2008; Jucker 2009). Further, Norrick (1978: 282-290) has provided a subdivision of expressive illocutionary acts based on the underlying emotions. Recently, Guiraud et al. (2011) have used an approach based on 
emotion theory and formal logic to systemize expressive speech acts from the point of view of underlying psychological attitudes with their main bases of joy, sadness, approval, and disapproval (loc. cit.: 1035). However, formal approaches to expressive speech acts do not seem to have been applied to and tested on corpus data yet.

The study of the pragmatics of Irish English in particular has made considerable progress during the last decade. A major piece of work on the pragmatics of Irish English to date is the volume edited by Schneider and Barron (2005), which focuses on descriptions of directness and politeness. Further, Kallen (2005) discusses politeness strategies in general. Very recently, the corpus based study of pragmatics has received a powerful tool in the shape of the pragmatically annotated version of ICE-Ireland, SPICE-Ireland (Kirk et al. 2011, Kallen and Kirk 2012).

Different research methods have been used to approach the collection of data for pragmatics research. One of these is to find possibly relevant structures by introspection, a method which has been referred to as the 'armchair method', (e.g. Jucker 2009: 1615). Further, data may be collected by laboratory based methods, such as discourse-completion tests or role-plays (Jucker 2009: 1618). In addition, various field methods may be used, such as the taking of field notes, investigating data in literary texts, employing conversation analytical methods, or indeed employing corpora (Jucker 2009: 1616). So far, corpus based research on speech acts has suffered from the shortcoming that only specific lexical items or very conventionalized patterns can be searched for with any ease (Jucker 2009: 1622). Thus, in the case of research on compliments, either the lexeme compliment itself may be searched for (Jucker 2009: 1616-1618), or specific search strings may be employed to search for corpus patterns in the corpus interface (Jucker et al. 2008; Jucker 2009: 1622). These, however, are given to overgenerating and require manual filtering and, even more detrimental for the retrieval of examples, these search strings miss out on relevant examples which do not conform to the searched-for pattern (ibid.). These problems are considerably alleviated by the creation of pragmatically tagged corpora such as SPICE Ireland (Kallen and Kirk 2012), which allow the researcher to restrict the amount of relevant data by using specific tag searches.

It is this new corpus that provides the data for the current study of expressive speech acts. In this study, we formalize expressive speech acts on the basis of corpus data from SPICE-Ireland. The aim of the study is primarily to offer a corpus based classification of the different uses of expressives and secondarily to investigate these expressives in order to assess to what extent they are used in three spoken categories of Irish English. The main thrust of the study is to help 
us to determine different subcategories of expressives and to assess these frequencies in the corpus data in order to allow for future comparison of cross-varietal differences, as well as for in-depth comparison of the different categories that are suggested. The intended perlocutionary effects of the utterances in relation to the social functions of the speech acts (cf. Norrick 1978: 280-282) will not be the centre of our attention here. The general background of speech acts and expressives are explained in Section 2. Section 3 introduces the data and methodology used in this study, and Sections 4 and 5 present and discuss the data obtained in the study.

\section{Expressive speech acts and their categorization}

Searle (1969) observes that verbal utterances are normally used to describe the world around us, but they may also encourage people to do things, or even constitute actions themselves, e.g. where a marriage is pronounced by a speaker who by his office is empowered to do so, or when a ship is named in a ship-naming ceremony. In later work, Searle (1976) distinguishes five types of speech acts in detail. These are representatives, directives, commissives, expressives and declarations.

Representative speech acts are utterances in which the speaker's words mirror the world truthfully (Searle 1976: 10; example (1)). Second, there are directive speech acts, which lead the recipient to carry out a task (example (2)). Implicitly, this also refers to questions, which intend to produce a reaction on the receiver's part, and to implicit directives which are encoded by implicatures (Searle 1976: 11), such as e.g. the statement it is very cold in here, which might imply that the recipient should close the window. Third, by using a commissive speech act, the speakers promise to undertake a certain action and in that way they make the world fit their words (Searle 1976: 11; example (3)). A further category of Searle's speech acts are declarations. These, if uttered by a person with the appropriate authority under certain well-defined circumstances, create situations that fit the words, e.g. a judge sentencing someone in a courtroom or a member of the clergy baptizing a child in church (Searle 1976: 13; example (4)).

(1) We were at a badminton match the other night (ICE IRE P1A-064\$E, Kallen and Kirk 2012: 29)

(2) Look at your vegetables, ... (ICE IRE P2A-056\$A, Kallen and Kirk 2012: 30) 
(3) So hopefully I'll get the Higgins uhm left in for you some time next week. (ICE IRE O1B-002\$A, Kallen and Kirk 2012: 31)

(4) I wish to record publicly my gratitude for their unfailing support for me and my work (ICE IRE P2B-041\$A, Kallen and Kirk 2012: 33)

The category with which the present paper is concerned is expressive speech acts. They are speech acts that express the speaker's feelings about themselves or the world (Searle 1976: 12). Norrick (1978: 279) specifies that expressive speech acts express psychological conditions, and thus not beliefs or intentions, which arise to given states of affairs. Some expressive speech acts have also been discussed by Taavitsainen and Jucker (2010), who treat $18^{\text {th }}$ century English, and concentrate on the use of politeness and on thanking, and who define expressives as expressing the state of mind, the attitudes, and the feelings of speakers (Taavitsainen and Jucker 2010: 159), such as:

(5) $<\#><\exp >$ Okay* sorry about that $</$ exp $>(<$ SPICE IRE, P1B$013 \$ \mathrm{~A}>$ )

In further research, Clark (1996: 134-135) adds that Searle's categories are not unified, but consist of different subgroups. Thus representatives, called assertives by Clark, clarify the speaker's belief, but can, amongst others, also express diagnoses, predictions, notifications, confessions or denials (Clark 1996: 134). While commissives mainly commit the speaker to further action and offer a promise, according to Clark directives can be further divided into the major subgroups of requests for action and requests for information (ibid.). Searle's declarations are divided into two distinct categories, effectives and verdictives. Clark argues that verdictives apply rules within an institution, e.g. a referee's ruling in a match must be obeyed (Clark 1996: 135). Other illocutionary acts which are typically associated with verdictives are acquitting, assessing, certifying, grading, ranking or ruling (Bach and Harnish 1979). In effectives, a change takes place which is not confined to the institutional setting, like a boss hiring or firing employees (Clark, ibid.). In the context of effectives, Bach and Harnish (1979) mention e.g. banning, censoring, firing, moving, sentencing or voting.

In describing expressives, Clark, too, refers to thanking, apologizing, congratulating and greeting (1996: 134). Four different events of speaker-hearer interaction lead to the use of expressive speech acts. First, this is a hearer being offended by something, which calls for the expressive speech act of apologizing. Second, a hearer achieving something positive, which leads to the speech act of congratulating. Third, a hearer doing a favour to the speaker which leads to the 
act of thanking and finally a hearer approaching the speaker which leads to the expressive act of greeting (Clark 1995: 193).

There have been approaches during the history of pragmatic research which have discussed different groupings within the types of speech acts. An early differentiation of expressive speech acts has been carried out by Norrick (1978). His definition of expressive speech acts is that of

A state of affairs X perceived as factual and judged to have positive or negative value for some person, the patient, brought about by a person, the agent (who may be identical with the patient), and, just in case either the agent or patient role is not filled or both are filled by the same individual, an additional person, the observer (Norrick 1978: 283).

From this, Norrick (loc.cit.: 284) creates the schema, where [items] are optional, and /value/ may be positive or negative:

$$
\text { (agent) /value/ X (patient) (observer), }
$$

in which 'value' can stand for a positive or a negative. According to this formula, he compares nine different kinds of expressive illocutionary acts. These are

1. Apologizing, where an agent-speaker expresses negative feelings towards a patient-addressee to appease them (Norrick 1987: 284)

2. Thanking, where the speaker expresses positive feelings to the addressee, who has done a service to the speaker (loc. cit.: 285)

3. Congratulating, where the speaker has observed that the addressee has either benefitted from or carried out a positively valued event (loc. cit: 285286)

4. Condoling, which resembles congratulating, except that the experienced event is negatively valued (loc. cit.: 286-287)

5. Deploring, or censoring, in which the addressee is criticised for an event which had a negative impact on the speaker or a third person (loc. cit.: 287288)

6. Lamenting, where the speaker expresses his or her own misfortune, either at their own or somebody else's doing, the speaker is also the main observer (loc. cit.: 288-289)

7. Welcoming, where the speaker expresses positive feelings towards the arrival of the addressee. Norrick (1987:289) points to the conceptual similarity with thanking. 
8. Forgiving, which is found to have a similar conceptual set-up as deploring, except for the fact that the speaker does not resent the addressee's action (loc. cit.: 289-290) and

9. Boasting, where the speaker expresses positive feelings about his or her own actions towards and addressee.

This classification proves helpful for our approach, even though not all our examples are covered by this classification, and a number of Norrick's classes are not found in the corpus material.

In a later study, Searle and Vanderveken (1985: 179-216) offer a semantic analysis of different types of English speech act verbs, considering assertives (called representatives in Searle 1976), commissives, directives and declaratives, as well as expressives. Concerning expressive verbs, Searle and Vanderveken find that no illocutionary verb or performative names the primitive expressive force, rather they name derived expressive forces (1985: 211). Expressive speech act verbs, they argue, usually either express good or bad evaluations, and they are hearer centred (ibid.). Examples of expressive speech act verbs are e.g. apologize, console, congratulate, lament, praise, greet or welcome (1985: 211-216).

In a recent approach, the subdivision of expressives has been formalized in a formal-cognitive approach by Guiraud et al. (2011) on the basis of Vanderveken's (1990) work. From this, Guiraud et al. create a formalization of expressive speech acts within the framework of modal logic of communication. The authors define expressive speech acts as public expressions of emotional states (2011: 1031) and outline the cognitive structures of the different emotions behind expressive speech acts. In their approach they take up Searle's (1969) assertion that ' $[\mathrm{w}]$ henever there is a psychological state specified in the sincerity condition, the performance of an act counts as an expression of that psychological state' (Searle 1969; quoted from Guiraud at al. 2011: 136). The emotional states are divided into two main types, basic emotions and complex emotions. Basic emotions derive from beliefs, goals and ideals of an agent. When agents believe something to be true, they feel joy or sadness at it being true, if agents hold something to be an ideal or not ideal state of affairs, they feel either approval or disapproval (loc. cit.: 1035). Thus for example joy is defined as a situation where an agent's belief in a situation being true coincides with the same agent's desire for the situation to be true. Sadness on the other hand is defined as an agent's desire for something to be true but believing that it is not (ibid.). Complex emotions are based on norms, responsibilities and further factors (ibid.). In what follows, Guiraud et al. formalize the expression of the basic 
emotions with references to Vanderveken (1990). The particular significance of their approach lies in the fact that, like Norrick (1978), they formalize expressives, and they do so on the basis of the different underlying emotions. Guiraud et al.'s (loc. cit.: 1036) basic emotions are joy, sadness, approval and disapproval. These lead to the distinction of the following expressive speech acts, whose theorems and formulae (loc. cit.: 1037) are here summed up in simplified form:

- Being delighted is defined as an agent expressing joy about reaching a goal to a hearer.

- Being saddened is defined as an agent expressing to a hearer sadness about an outcome that has not been aimed for by the agent.

- Approving is defined as an agent expressing approval to the hearer about an ideal that has been reached .

- Disapproving is defined as an agent expressing disapproval to the hearer about something that is not considered ideal.

- Being sorry is defined as the agent expressing to a hearer regret that the hearer did not reach a goal.

- Sympathizing is defined as an agent expressing to the hearer regret that the hearer did not reach a goal and the agent has the same goal as the hearer.

Guiraud et al. further identify complex emotions based on the agent's beliefs that their own responsibilities lead to their goals or ideals either coming true or not. The underlying emotions are rejoicing, gratitude, regret, disappointment, moral satisfaction, admiration, guilt and reproaching (2011: 1035-1037). These complex emotions lead to the expressive acts of rejoicing, thanking, regretting, deploring, apologizing, expressing moral satisfaction, complimenting, expressing guilt, reproaching, accusing and protesting (2011: 1037). In this particular study, the authors give few linguistic examples and the discussion is theoretical and centers on a survey of basic and complex emotions and the logic formulae behind these, there is no application to either corpus or constructed data. The application of such theoretical approaches to corpus data is now greatly facilitated by the release of SPICE Ireland with its pragmatic tagging.

The tagged expressives in SPICE Ireland capture those examples which "express the psychological state specified in the sincerity condition about a state of affairs" in which "the speaker is neither trying to get the world to match the words nor the words to match the world" (Searle 1976: 12; Kallen and Kirk 2012: 32). Kallen and Kirk (ibid.) point out that contextual features including prosody may be vital for the identification of a speech act as an expressive. In 
spite of this prosodic information, it is not always possible or indeed useful to determine one single speech act only, as in one utterance more than one speech act may be identified. Thus, in the case of an utterance like I'd like to produce materials (ibid.) it may be difficult to decide whether this utterance should be considered an expressive that makes a statement about speaker's desires and feelings, or whether it should be analyzed as a representative that states a true proposition, or whether it might even be a directive under the appropriate circumstances. In order to resolve this ambiguity, contextual features must be taken into account. Kallen and Kirk caution that this taking into account of contextual features may broaden the tagged category of expressives in SPICE-Ireland beyond Searle's definition as the "interpretive principle of contextual effects extends the expressive category beyond the core examples of Searle's definition" (Kallen and Kirk 2012: 32). This explicitly broad approach further implies that categories that would not be covered by Guiraud et al.'s theorem discussed above may appear as expressives in the corpus material. Conversely, it has also emerged that some of Guiraud et al.'s categories are not in evidence in the corpus material, or that the required complex psychological background may not be sufficiently identifiable. The current approach tries to reconcile a structural approach like that by Guiraud et al. with a data driven approach in which Guiraud et al.'s basic emotions sadness, joy and approval and disapproval, as well as sympathy, are reevaluated against the corpus material. In order to comprehensively categorize the material, further categories are used here and these are presented in section 4 .

In the SPICE-Ireland corpus, a certain number of utterances could not be related to any of the above speech acts. This holds, for example, for back-channels and other conversationally necessitated response types. These are termed indeterminate conversationally-relevant utterances, annotated as $<$ icu $>$ (Kallen and Kirk 2012: 33). The authors and annotators further introduce a separate category of social utterances including greetings, tagged $<$ soc $>$, as well as a special group of utterances of humorous or ironic utterances with an extra tag added on to the basic identification (loc. cit.: 34 ). Some utterances remain unanalyzable, such as false starts or audibly incomprehensible source materials, these are tagged as $<$ xpa $>$ (ibid.).

\section{$3 \quad$ Data and methodology}

As indicated in Sections 1 and 2 above, SPICE-Ireland (Kirk, Kallen, Lowry, Rooney and Mannion 2011) has been created on the basis of the 1 million word ICE-Ireland corpus, but it contains only the 300 files of the spoken categories, 
each consisting of about 2,000 words (Kallen and Kirk 2012: 9). It offers tonal and pragmatic annotations. Concerning pragmatic annotation, Kallen and Kirk (2012: 94) state that a total of about 54,600 speech acts have been annotated in the corpus. All of these can be conveniently culled from the data base by searching for the tags $<$ rep $>$ for representatives, $<$ dir $>$ for directives, $<$ exp $>$ for expressives, $<\mathrm{com}>$ for commissives, and $<\mathrm{dec}>$ for declarations, which Kallen and Kirk (2012) term declaratives. Indeterminate units are marked as $<\mathrm{idu}>$, incompletes are marked as $\langle\mathrm{xpa}>$. The current study is entirely corpus-driven. In order to collect and evaluate the tagged expressives in SPICE Ireland, the expressive tags $<\exp >$ were searched with the help of the concordance programme AntConc 2 (Anthony 2004). As a detailed investigation of all instances of expressives in ICE Ireland would be too extensive for this study, we will concentrate on expressives in the spoken registers of rather formal broadcast discussions (20,000 words each from both Northern Ireland and the Republic of Ireland), less formal class-room discussions (20,000 words each) and a corresponding number of files of the informal face-to-face conversations (20,000 words each, categories P1A 001-10 and P1A-046-55).

While this is convenient, searching by tags has the disadvantage that potentially relevant items which may not have been separately tagged as expressives are missed out on. This may refer in particular to categories like greetings, which Clark (1996: 135) subsumes under the heading expressives. Kallen and Kirk (2012: 34), by contrast, tag these among social expressions, $<$ soc $>$. Further, the editors caution that they use a broader application of the term expressive than Searle (1976), which Kallen and Kirk argue to be due to the fact that in comparison with Searle's constructed data the natural data are less clear-cut and necessitate broader category labels (Kallen and Kirk 2012: 32). Thus some examples may not be unanimously considered to be expressives by all researchers. In other examples, prioritizing expressivity may seem open to question to readers, as e.g. in $</ \&><\mathrm{P} 1 \mathrm{~B}-040 \$ \mathrm{~B}><\#><\exp >$ Welcome back to It 's Friday $</ \exp >$, which might be viewed as a social utterances $<$ soc $>$, described as being used for greetings, leave-takings and other interactive expressions (Kallen and Kirk 2012: 34). Finally, some items may also represent multiple speech acts, but can only be tagged as one type of speech act in the corpus. Thus an item which also functions as an expressive in addition to other categories might not have been tagged as such and might consequently have been missed out on in this analysis. This feature may impact on the overall count of examples as certain examples which may also be considered expressives may have been tagged according to their major pragmatic form only. In assessing this, the annotators' choice will of course have played a major role. This, however, does not diminish 
the general usefulness of the data source as the numbers of tagged expressives are considerable in the corpus and provide an extremely useful data base. It is not the aim of this study to re-assess the annotated tokens in the corpus. We rely on the careful and consistent annotation (Kallen and Kirk 2012) which is provided and accept it as gold standard. In the present study, the semi-automatically extracted expressives have been manually further classified into various semantic categories, informed by Norrick's (1978) and Guiraud et al.'s (2011) categories. The collected examples are described below.

\section{Types of expressive speech acts in SPICE Ireland}

Kallen and Kirk's survey shows that of a total of about 54,600 speech act notations, 1242 examples of expressive speech acts are found in SPICE Ireland (2012: 94), accounting for 2.3 per cent of the total speech acts. By far the highest number are representatives (64.4 per cent), 19.1 per cent are directives, 6.8 per cent are indeterminate, 4.6 per cent are incomplete utterances. Commissives and declarations are at 1.2 per cent and 0.2 per cent respectively. As indicated in section 3 above, the expressives investigated here are taken from 10 roughly 2,000 word files each of southern and northern data. The data totals 120,000 words and is taken from broadcast discussions, classroom discussions and faceto-face conversations in order to allow a broad overview of examples from formal, semi-formal and informal settings.

According to Guiraud et al. and Norrick's approach, we divided the expressives culled from the SPICE Ireland data into eight categories. These categories comprise Guiraud et al.'s basic expressive categories delight and approval, as well as sadness and disapproval and feeling sorry and sympathizing, which can be identified in the corpus material with sufficient confidence. Identification of the further complex emotional categories identified by Guiraud et al.'s on the basis of the corpus material is more difficult, however. The psychologically complex categories happiness (rejoicing), gratitude, regret, deploring, apologizing, moral satisfaction, complimenting, feeling guilty, reproaching and protests (2011.: 1036-1037) are explained logically by the researchers, but are difficult to distinguish from each other in the corpus material and have consequently been regrouped for the current approach. Conversely, other expressive categories appearing in the corpus are not treated by Guiraud et al. This is particularly true for utterances attested in the corpus denoting volition and exclamations. The categories are discussed below. 


\subsection{Agreement}

In the investigated data, the most frequently attested category is the expression of positive attitudes either towards a person or a proposition. These are here termed agreement, and while they find no correspondence in Norrick's classification, they seem to correspond to Guiraud et al. 's category approval. This category could have been separated into liking, expressing attitudes towards a person or thing as in I like her too < 1 1B-015\$? > and agreement, expressing agreement with a proposition, e.g.:

(6) $<\#><\exp >$ Yes* I I $<$.> thi $</>$ agree with uh Dr Fitzgerald $<$ exp $>$ $(<\mathrm{P} 1 \mathrm{~B}-034 \$ \mathrm{E}>)$

This possible subdivision has not been used here and liking a proposition and a person are considered together. This is done on the grounds that the emotion is positive in both cases, but in the case of liking, it is directed towards a person or thing, in the case of agreement it is directed towards a proposition.

Further we might have related to the expressions of agreement also compliments to an interlocutor. These are well-established expressive speech acts, which are discussed by various authors (Searle and Vanderveken 1985: 212213; Jucker et al. 2008; Jucker 2009). However, no examples have been found within the expressive categories in the corpus files in the present data.

\subsection{Disagreement}

In addition to the category agreement we find corresponding expressions of negative values, Guiraud et al.'s disapproval. They may correspond to the category termed deploring by Norrick (1978: 287). Examples can be seen in (7):

(7) $<<\#><\exp >$ I 'm just\%* I 'm 1vEry disappointed in the 2Unionists ' response $\%</ \exp >(\mathrm{P} 1 \mathrm{~B}-022 \$ \mathrm{G}>)$

Overall, examples of agreement predominate over those of disagreement, but the difference between agreement and disagreement does not reach significance levels. What is very notable, however, is the marked avoidance of uttering explicit disagreement. While in face-to-face conversations, disagreement is most likely to be explicitly expressed, as in 11 don't 2 agrEE with it $\%(<\mathrm{P} 1 \mathrm{~A}$ $005 \$ \mathrm{~A}>$ ), in the less intimate classroom discussions it was more typical for the speakers not to downright contradict or criticize a proposition. Instead, the speakers more typically claimed they did not know, and thus questioned the truth-value of the proposition: 
(8) $<\exp >$ Uh uh I don't know if this is true now or not $</ \exp >(<$ P1B$014 \$ \mathrm{E}>$ )

(9) $<\exp >$ Uhm $<$, $>$ we don't know whether there will be uh internal choice $</ \exp >(<$ P1B-015\$A $>)$

In broadcast discussions, where the topics are often political, direct disagreement can only be found in 1 case of the 14 examples of disagreement (example (10)), while the other examples also express insecurity about a proposition (11).

(10) $<\exp >$ No I 'm afraid I disagree with you $\ldots</ \exp >(<$ P1B-027\$C $>)$

(11) $<\exp >$ and I'm not too sure that we can $<$, > </exp $>(<$ P1B-033\$I $>)$

This preference of oblique disagreement seems to confirm that open disagreement is shunned and thus supports the observation that face saving is important in Irish English (Farr and O'Keeffe 2002). It also confirms Kallen's (2005) observation that politeness strategies in Irish English emphasize group identity markers and conventional optimism (2005: 142-143). However, it is also well known that agreement and politeness are general trends in human communication, which means that face-threatening acts are typically avoided (Brown and Levinson 1987), and not only in Irish English. Jing-Schmidt (2007) has likewise shown that humans in general tend to use positive comments in discourse. On the one hand she argues that a bias for positive conversation topics is a phenomenon of socialization. This phenomenon is identified as being due to the desire to create pleasant surroundings for ourselves. On the other hand Jing-Schmidt identifies social constraints of maintaining face, politeness and self presentation as driving forces of this phenomenon (2007: 422-424). Thus in order to show how much more prominent agreement really is in Irish English than in other varieties, we would need to compare counts of agreement and disagreement in Irish English with the respective counts in other varieties of English.

\subsection{Volition}

A further large group of examples was conspicuous in the corpus data even though both Norrick (1978) Guiraud et al. (2011) do not provide a corresponding category, namely the expression of volition. It might be argued that having a wish deviates from Norrick's definition that expressives should not express emotions that are directed at future states (Norrick 1978: 279). Conversely, however, we may argue that wishes in fact express ideals that the speaker has, but which are not matched by the state of affairs. We may formalize this as 
an agent having an ideal of the event being true which is not true at the moment.

Predictably, large numbers of examples expressing volition are found in the twenty files stemming from the broadcast discussions (38 examples), fewer in the twenty files each from face-to-face ( 9 examples) and classroom discussions (11 examples). In the classroom discussions, the most explicit example (14) comes from lecturer-student interaction on hand-in dates of essays.

(12) $<\exp >$ Now* 1 hAving got a 1gOvernment 1 estAblished $\%$ 1I also want to see the $1 \mathrm{fUll} 1$ stOry come $10 \mathrm{OUt} \% \ldots</ \exp >(<\mathrm{P} 1 \mathrm{~B}-032 \mathrm{SD}><)$

(13) $<\exp >$ We want to see progressive politics here $</ \exp >(<\mathrm{P} 1 \mathrm{~B}-$ $027 \$ \mathrm{C}>$ )

(14) $<\#><\exp ><[>$ Yeah* $<$, $>$ no* I would 11Ike you to 2 sEE it before $\%$ $</[></\{><,>2$ befOre that time $\% \ldots</ \exp >(<\mathrm{P} 1 \mathrm{~B}-002 \$ \mathrm{~A}>)$

Example (14) in this group is also a good example of Kallen and Kirk's (2012: 35 ) point about the inherent ambiguity observable in many examples. While the wish of the speaker is clearly expressed, the expression of this wish may also be used as a directive towards the addressee of the utterance.

\subsection{Thanking}

A group which is well-established as expressive speech acts is that of expressing gratitude or thanks (Norrick 1978: 284-285; Searle and Vanderveken 1985: 212; Guiraud et al. 2011: 1036-1037). In the interactions in the current corpus material, numerous examples of these can be found, as in:

(18) $<\#><\exp >$ Okay* uh 1thAnks very 1 mUch Gerard $<\exp >(<$ P1B$031 \$ \mathrm{~B}>$ )

In the broadcast discussions and classroom discussions considered here, thanking is typically found at the close of either a turn or a sequence. This predominance in closing sequences is likely to be due to genre specific preferences because typically either students or reporters receive the teacher's or presenter's thanks at the end of their contribution. This can be illustrated by the following example:

(19) $<\#><$ dec $><$ [ $>$ Okay* well* $<$, $>$ we 'll have to leave it there $<$. $>$ Mich $</ .></[></\{></$ dec $><\#><\exp >$ Okay* Michael Farrell in Dublin thanks very $1 \mathrm{mUch} \%</ \exp ><\#><$ icu $>$ Brian D'arcy Bill Rolston $1 \mathrm{hEre} \%<$ icu $><\#><\exp >$ Thank-1yOU\% $</ \exp >(\mathrm{P} 1 \mathrm{~B}-021 \$ \mathrm{~A}>)$ 
In face-to-face conversations, these expressions of gratitude also refer to items and actions or actors who do not participate in the conversation, such as

(20) $<\&>\$ C$ speaks to waitress $</ \&><\#><\exp >$ Thank-you $</$ exp $>$ $(<\mathrm{P} 1 \mathrm{~A}-010 \$ \mathrm{C}>)$

(21) $<\#>(<$ rep $>$ Hmm I was only $<$, $>$ giving her credit $<$ rep $><\#><$ rep $>$ Roisin was there $</$ rep $><\#><$ rep $>$ Roisin 's face $<,>)<\exp >$ no thanks $<$, $>(</ \exp >$ Roisin 's face was really funny $</$ rep $>)(<\mathrm{P} 1 \mathrm{~A}-$ $053 \$ \mathrm{~A}>$ )

\subsection{Apologizing}

Further routine formulae of expressives in the data are constituted by expressions of being sorry, by apologies. This category of expressive speech acts is well-documented (Norrick 1978: 284-285; Searle and Vanderveken 1985: 211212). In the corpus data, apologies particularly occur in the case of speech production errors and subsequent repairs (22), but also examples of interactional apologies are found $(23,24)$.

(22) $<$ exp $>$ Okay* $<$,> sorry two pounds per $u h m<$, > per offprint $(<$ P1B$015 \$ \mathrm{~A}>$ )

(23) $<\&>\$$ A drops knife $</ \&><\#><\exp >$ Sorry $<$ exp $>(<$ P1A-009\$ $>)$

(24) $<\#><\exp >$ I lapOlogise if I $1 \mathrm{dOn}$ 't $\%$ because the 1 twO gentlemen here in 1BElfast have a 110 to 1 Answer $\%<,>$ from Seamus $1 \mathrm{MAllon} \%$ and and the $1 \mathrm{gIst}$ of it $2 \mathrm{sEEms}$ to $2 \mathrm{bE} \%$ the $1 \mathrm{wEAkness}$ of the 1Unionist 11EAdership\% </exp> (P1B-030\$A $>$ )

With 24 examples in 40 investigated files of face-to-face conversations and 17 examples in the overall 40 files of classroom discussions, there are considerably more examples than in the broadcast discussions (three examples). Face-to-face conversations seem to use the apologies largely for organizing personal interaction, broadcast examples use the apologies in repair structures, but also to offer real apologies to second or third parties. In the classroom situation we also find examples of repairs (example (22) above), and signals for turn-taking, as in $I$ think it would seem to be outside sorry Eleanor (S1B-001:1:35:A), where an instructor cedes the floor to a student.

\subsection{Non-directed complaints in exclamations}

Further groups of examples tagged as expressives in SPICE Ireland are exclamations which contain religious or non-religious expletives. On the one hand, 
such religious expressions or other expletives, like e.g. oh Jesus, or bloody X may be discourse markers. As such, they can be part of any type of speech act and do not receive any special, separate tagging in SPICE Ireland. On the other hand, SPICE Ireland contains examples of religious expressions or swear words which appear as stand-alone exclamations. As such they denote the speakers' agitation and may be described as invocations. They might also be described in terms of Guiraud et al.'s terms as reproaches: according to Guiraud et al. (2011: 1037) reproaching is the utterance of a reproach by an agent directed towards a hearer. Arguing with Guiraud et al. here and considering this category purely in terms of reproaches would mean to disregard the potentially invocative aspect of such examples, which may also be an appeal for a higher being's protection.

$$
\begin{aligned}
& \text { (25) }<\#><\exp >\text { Oh holy }<\{><[>\text { Jaysus }</[></ \exp >(<\text { P1A-051\$A }>) \\
& \text { (26) }<\#><\exp ><[11>\text { Oh* bless us }</ \exp >(<\text { P1A-047\$B }>)
\end{aligned}
$$

Numerous such exclamations (31 examples) are found in face-to-face conversations (e.g. example (25) above), only one example is found in broadcast, and five examples in classroom discussions. In accordance with Farr and Murphy (2009), we can predictably observe a strong split in the uses of these items between the more formal text types with fewer tokens and the less formal text types with more tokens. But we believe that a case can be made on the basis of the data to postulate a category of expressives consisting of exclamations, which may comprise expletives and other emotionally charged utterances, such as those tagged expressives in the corpus data which are other swear words. Not only in Irish English, but in other varieties as well (Wierzbicka 2002; Murphy 2009) certain swear words may have extended beyond swearing towards discourse-marker usage (cf. Murphy 2009). But here, again, we find numerous stand-alone examples of these swear words which may have a reproaching or perhaps partly invocative function. In the face-to-face conversations there was a range of examples, including moderate and highly colourful ones:

$$
\begin{aligned}
& <\#><\exp >\text { Crikey }</ \exp >(<\text { P1A-048\$A }>) \\
& <\#><\exp >\text { Well* feck me tiny anyway }</ \exp >(<\text { P1A-050\$B }>)
\end{aligned}
$$

In the more formal class-room discussions the only example of such an exclamation is in French:

(29) zut (French, $<$ P1B-015\$A $>$ )

Information on the linguistic background of this particular speaker is not given in the SPICE guide (Kallen and Kirk 2012: 84). The use of French could be due 
to the linguistic background of the speaker, or else it could be due to avoidance of a taboo word, which would be considered situationally inappropriate for being embarrassing or offensive (Crystal 2006: 127-133). As far as these exclamations, which are tagged as expressives, are concerned, it is not surprising to see that their number in the corpus material increases with a decreasing level of formality of the situation.

\subsection{Expressing sorrow}

A category that is less-frequently found in the corpus data is the expression of sorrow or feeling sad. Norrick (1978: 286-287) identifies this group as condoling, Guiraud et al. posit a similar basic category of sympathizing, which is defined as being sad on account of another person (Guiraud et al. 2011: 1036). In addition to this group, Norrick (1978: 288-289) posits the expression of sorrow not on somebody else's behalf, but on one's own behalf, which he calls lamenting. We have here found only two examples of lamenting and two of condoling, and have decided to collapse these two as it does not seem immediately obvious in all examples whether sadness is to be understood as being on account of oneself (as in (30)) or of another participant (31). Examples are given in the following:

(30) $<\#>(<$ dir $>$ See where they 're taking the shamrock off the $<\{><[>$ tail and $<$. $>$ every $</$. $></$ dir $>$ ) $<\#><\exp >$ I-think $*</[$ that 's $<,>$ I-think $*$ that 's awfully sad to see that $</ \exp >(<$ P1A-004\$A $>)$

(31) $<$ \#> $(<$ com $>$ I can't believe $<,></$ com $>)<\exp >$ the poor guy $</ \exp >$ $(<\mathrm{P} 1 \mathrm{~A}-007 \$ \mathrm{~A}>)$

The low attestation of expressions of sorrow could be due to corpus sampling and may additionally have been influenced by file selection for the current study, but it is of course also possible that there are cultural constraints against the public expression of feeling sorrow.

\subsection{Greetings}

Further, Clark (1996: 135) subsumes greetings amongst the category of expressives. There are only two examples of a greeting in the corpus data, namely:

(32) $<\exp >$ Welcome back to It 's Friday $</ \exp >(<$ P1B-040\$B $>)$

(33) $<\exp >$ Happy Halloween $<,></ \exp >(<$ P1A-050\$C $>)$

The fact that there are very few greetings in our corpus material might be somewhat influenced by the circumstance that the tag-set that is used by Kallen and 
Kirk (2012) also contains a category <soc $>$, social expressions, which also comprises "[g]reetings, leavetakings, and other interactive expressions" (Kallen and Kirk 2012: 34). As our present approach explicitly only considers those items which are tagged as expressives in the corpus, possible greetings that might be tagged as $<$ soc $>$ have not been taken into account here.

\subsection{Further categories}

In addition to the categories which have been discussed above, some examples of tagged expressives were found in the SPICE Ireland data, which did not fit any of the proposed categories. On the one hand these were examples which comprised particularly expressions of understanding, as in (34) below, but also examples of unclear expressive force, as in (35):

(34) $<\mathrm{X}><\#><\exp >$ I can understand it 's just frustration $<\exp >(<\mathrm{P} 1 \mathrm{~B}-$ $025 \$ \mathrm{~L}>$ )

$$
<\#><\exp ><[>\text { Aw }</[></\{></ \exp >(<\text { P1A-048\$B }>)
$$

There are three remaining categories which Guiraud et al. (2011) have postulated, happiness (rejoicing), feeling guilty and moral satisfaction. Examples of happiness and feeling guilty are in fact found in the SPICE Ireland corpus, e.g.:

$$
\text { (36) }<\#><\exp >\text { I' } m<\{><[>\text { delighted }</[></ \exp >(<\text { P1A-068\$B }>)
$$

However, these examples were found only outside those files that were used for the current evaluation (see Section 3) and therefore cannot form part of this study. Further, there were no examples of Norrick's categories congratulating, forgiving and boasting, nor of compliments, in the investigated corpus files.

\section{Overview of expressive speech acts in the data}

The frequencies of the overall use of expressive categories in the corpus material, comprising 40,000 words each per category, are displayed in Table 1. 
Table 1: types of expressives in SPICE Ireland categories of 40,000 words each

\begin{tabular}{|l|l|l|l|l|l|l|l|l|l|l|}
\hline Category & $\begin{array}{l}\text { Agree } \\
\text {-ment }\end{array}$ & $\begin{array}{l}\text { Dis- } \\
\text { agree- } \\
\text { ment }\end{array}$ & $\begin{array}{l}\text { Voli- } \\
\text { tion }\end{array}$ & Thanks & Apologies & $\begin{array}{l}\text { Exclama- } \\
\text { tions }\end{array}$ & Sorrow & $\begin{array}{l}\text { Greet- } \\
\text { ings }\end{array}$ & Unclear & Totals \\
\hline $\begin{array}{l}\text { Broadcast/ } \\
40,000 \text { words }\end{array}$ & $\begin{array}{l}18 \\
(20 \%)\end{array}$ & $\begin{array}{l}14 \\
(16 \%)\end{array}$ & $\begin{array}{l}38 \\
(42 \%)\end{array}$ & $\begin{array}{l}11 \\
(12 \%)\end{array}$ & $\begin{array}{l}3 \\
(3 \%)\end{array}$ & $\begin{array}{l}1 \\
(1 \%)\end{array}$ & 0 & $\begin{array}{l}1 \\
(1 \%)\end{array}$ & $\begin{array}{l}4 \\
(4 \%)\end{array}$ & 90 \\
\hline $\begin{array}{l}\text { Classroom/ } \\
40,000 \text { words }\end{array}$ & $\begin{array}{l}14 \\
(21 \%)\end{array}$ & $\begin{array}{l}17 \\
(25 \%)\end{array}$ & $\begin{array}{l}11 \\
(17 \%)\end{array}$ & $\begin{array}{l}3 \\
(4 \%)\end{array}$ & $\begin{array}{l}17 \\
(25 \%)\end{array}$ & $\begin{array}{l}6 \\
(9 \%)\end{array}$ & 0 & 0 & 0 & 68 \\
\hline $\begin{array}{l}\text { Face to face/ } \\
40,000 \text { words }\end{array}$ & $\begin{array}{l}26 \\
(20 \%)\end{array}$ & $\begin{array}{l}14 \%) \\
(11 \%)\end{array}$ & $\begin{array}{l}9 \\
(7)\end{array}$ & $\begin{array}{l}19 \\
(14 \%)\end{array}$ & $\begin{array}{l}24 \\
(18 \%)\end{array}$ & $\begin{array}{l}34 \\
(26 \%)\end{array}$ & $\begin{array}{l}4 \\
(3 \%)\end{array}$ & $\begin{array}{l}1 \\
(1 \%)\end{array}$ & $\begin{array}{l}(1 \%) \\
(1 \%)\end{array}$ & $\begin{array}{l}432 \\
(16 \%) \\
(20 \%)\end{array}$ \\
\hline $\begin{array}{l}\text { Total/ } \\
\text { words }\end{array}$ & $\begin{array}{l}58 \\
(20 \%)\end{array}$ & $\begin{array}{l}45 \%) \\
(11 \%)\end{array}$ & $\begin{array}{l}44 \%) \\
(14 \%)\end{array}$ & $\begin{array}{l}4 \%) \\
(1 \%)\end{array}$ & $\begin{array}{l}5 \\
(2 \%)\end{array}$ & 290 \\
\hline
\end{tabular}

1. One example has been left out of consideration because the type of expressive seems indeterminable $(<$ P1A-048\$B $><\#><\exp ><[>$ Aw $</[></\{></ \exp >)$.

Table 1 shows the suggested subdivisions of expressive speech acts in the three selected subcategories of SPICE-Ireland. Differences between these subcategories are highly significant at $\mathrm{p}<0.0001$ at $10 \mathrm{df}$ (according to chi-square contingency table), omitting the categories sorrow, greetings and unclear, which had too few tokens to be tested. Agreement and volition are the best-represented categories of expressive speech acts. These are followed by tokens of disagreement, apologies, by exclamations and by thanking. Exclamations and thanking are frequent particularly in face-to-face conversations. Expressions of sorrow, as well as greetings, are rare. Some examples remained unclassifiable. Distinct compliments, congratulations, boasts and expressions of forgiveness have not been found in the data.

Within the evaluated categories, differences in distribution within the text types can be found. This particularly concerns the higher use of exclamations and expressing thanks in the less formal, more interactional categories. It is also noteworthy that the expression of volition is prominent in broadcast discussions. The difference may be explained as genre specific, because broadcast discourse, particularly in the political context, is given to voicing opinions and intentions, while classroom discourse is largely concerned with transporting knowledge, and face-to-face conversation is largely concerned with social interaction. Further, a high incidence of apologies is observable in face-to-face conversations, this is partly due to apologies for issues arising in non-verbal interaction, such as apologies for obstructing someone's way or interrupting them. The relatively high incidence of apologies in classroom discussions could, on the one hand, be due to lecturers producing non-scripted discourse, which may necessitate 
repairs. On the other hand, classroom interaction is likely to contain a sizable number of signals for turn-taking such as sorry or excuse me.

\section{Conclusion}

This paper has investigated the use of expressives in a sample of formal, semiformal and informal discourse in Irish English taken from the SPICE Ireland corpus. Expressives form 2.3 per cent of the overall speech acts in that corpus. On the basis of the corpus data, eight distinct categories have been identified which partly correspond to a survey of different types of expressives by Norrick (1978) and on a previous classification based on formal-logic approaches used by Guiraud et al. (2011). Some categories introduced by these scholars are not in evidence in the corpus data, while other categories, which have not been suggested previously, seemed to prove necessary on the basis of the corpus data. This particularly concerns the expression of volition and of exclamations. The most frequently used expressives in the sample categories were those expressing agreement. Agreement is similar in frequency to expressions of volition, followed by disagreement and apologies, exclamations and by thanks. Expressions of sorrow and greetings were rare. The use of exclamations was particularly rare in the formal and semi-formal registers, the extent of the use exclamations in the corpus data therefore was clearly influenced by formality of the genre.

The findings of the corpus-based data suggest that the category of expressive speech acts contains a number of different categories that so far have received little attention. The discussion of these different subcategories raises further questions. On the one hand, we wonder whether particularly expressives need to be considered a rather diverse category of speech acts, or to what extent the diversity of other categories of speech acts should also receive more attention. On the other hand, the question arises in how far these different subcategories of expressives might show different functions and different usage patterns in language and communication. These lines of investigation are beyond the scope of the present article, but would certainly merit further research.

\section{References}

Anthony, Laurence. 2004. AntConc: A learner and classroom friendly, multiplatform corpus analysis toolkit. In L. Anthony, S. Fujita and Y. Harada (eds.). Proceedings of IWLeL 2004: An Interactive Workshop on Language e-Learning, 7-13. 
Austin, John L. 1962. How to do things with words. Oxford: Oxford University Press.

Bach, Kent H. and Robert M. Harnish. 1979. Linguistic communication and speech acts. Cambridge, Mass.: MIT Press.

Barron, Anne and Klaus P. Schneider. 2005. Irish English: A focus on language in action. In K. P. Schneider and A. Barron (eds.). The pragmatics of Irish English, 2-15. Berlin: Mouton de Gruyter.

Brown, Penelope and Stephen C. Levinson. 1987. Politeness: Some universals in language usage. Cambridge: Cambridge University Press.

Clark, Herbert. 1996. Using language. Cambridge: Cambridge University Press.

Crystal, David. 2006. Words, words, words. Oxford: Oxford University Press.

Farr, Fiona and Bróna Murphy. 2009. Religious references in contemporary Irish English: 'For the love of God almighty. . . . I'm a holy terror for turf'. Intercultural Pragmatics 6-4: 535-559.

Farr, Fiona and Anne O'Keefe. 2002. Would as hedging device in an Irish context: An intra-varietal comparison of institutionalised spoken interaction. In R. Reppen, S. M. Fitzmaurice and D. Biber (eds.). Using corpora to explore linguistic variation, 25-48. Amsterdam and Philadelphia: John Benjamins.

Guiraud, Nadine, Donimique Longin, Emiliano Lorini, Sylvie Pesty and Jérémy Rivière. 2011. The face of emotions: A logical formalization of expressive speech acts. In K. Tumer, P. Yolum, L. Sonenberg and P. Stone (eds.). Proceedings of the 10th International Conference on Autonomous Agents and Multiagent Systems (AAMAS 2011), May, 2-6, 2011, Taipei, Taiwan, 10311038. Richland, SC: International Foundation for Autonomous Agents and Multiagent Systems.

Jing-Schmidt, Zhuo. 2007. Negativity bias in language: A cognitive affective model of emotive intersifiers. Cognitive Linguistics 18 (3): 417-443.

Jucker, Andreas H. 2009. Speech act research between armchair, field and laboratory: The case of compliments. Journal of Pragmatics 41: 1611-1635.

Jucker, Andreas H., Gerold Schneider, Irma Taavitsainen and Barb Breustedt. 2008. Fishing for compliments: Precision and recall in corpus-linguistic compliment research. In A. H. Jucker and I. Taavitsainen (eds.). Speech acts in the history of English, 273-294. Amsterdam/Philadelphia: John Benjamins.

Kallen, Jeffrey L. 2005. Politeness in Ireland: ‘... In Ireland, it's done without being said'. In L. Hickey and M. Stewart (eds.). Politeness in Europe, 130144. Clevedon: Multilingual Matters. 
Kallen, Jeffrey L. and John M. Kirk. 2012. SPICE-Ireland: A user's guide. Belfast: Cló Ollscoil na Banríona.

Kirk, John M., Jeffery L. Kallen, Orla Lowry, Anne Rooney and Margaret Mannion. 2011. The SPICE-Ireland Corpus: Systems of pragmatic annotation for the spoken component of ICE-Ireland. Version 1.2.2. CD-ROM. Belfast: Queen's University Belfast and Dublin: Trinity College Dublin.

Murphy, Bróna 2009. 'She's a fucking ticket': The pragmatics of FUCK in Irish English - an age and gender perspective, Corpora 4 (1): 85-106.

Norrick, Neal R. 1978. Expressive illocutionary acts. Journal of Pragmatics 2 (3): 277-291.

Schneider, Klaus P. and Anne Barron. 2005. The pragmatics of Irish English. Berlin: Mouton de Gruyter.

Schneider, Klaus P. and Iris Schneider. 2000. Bescheidenheit in vier Kulturen: Komplimenterwiderungen in den USA, Irland, Deutschland und China. In M. Skog-Södersved (ed.). Ethische Konzepte und mentale Kulturen II: Sprachwissenschaftliche Studien zu Höflichkeit und Respektverhalten, 6580. Vaasa: Vaasan Yliopisto.

Searle, John. 1969. Speech acts. Cambridge: Cambridge University Press.

Searle, John. 1976. A classification of illocutionary acts. Language in Society 5: $1-23$.

Taavitsainen, Irma and Andreas H. Jucker. 2010. Expressive speech acts and politeness in eighteenth century English. In R. Hickey (ed.). Eighteenth Century English: Ideology and Change, 159-181. Cambridge: Cambridge University Press.

Vanderveken, Daniel. 1990. Principles of language use. Cambridge: Cambridge University Press.

Wierzbicka, Anna. 2002. Australian cultural scripts - bloody revisited. Journal of Pragmatics 34: 1167-1209. 